\title{
Editorial
}

\section{Co-existence of genetically modified crops with conventional and organic farming}

\author{
Joachim SCHIEMANN \\ Federal Biological Research Centre for Agriculture and Forestry (BBA), 38104 Braunschweig, Messeweg 11-12, Germany \\ E-mail: j.schiemann@bba.de
}

\begin{abstract}
What has the co-existence of GM and non-GM crops to do with environmental biosafety? A clear distinction has to be made between the economic aspects of co-existence and the environmental and health aspects of GMOs. Nevertheless, since both the co-existence and the biosafety areas are often based on the same scientific knowledge (e.g. regarding gene flow) and EBR is interested in the socio-economic impact of GMO use as well, EBR is open for reflections on co-existence of GM and non-GM crops.

The cultivation of authorized GM crops will have an impact on agricultural production. It raises the question of how to manage the adventitious mixing of GM and non-GM crops as well as the possible economic consequences, at least in Europe. Farmers should be able to cultivate the crops they choose, be it GM, conventional or organic crops. The ability of the agricultural sector to maintain different production systems is fundamental for providing a high degree of consumer choice.
\end{abstract}

\section{CONCLUSIONS AND RECOMMENDATIONS FROM THE CO-EXISTENCE ROUND TABLE IN BRUSSELS IN APRIL 2003}

A Round Table on Research Results Relating to Coexistence of GM and Non-GM Crops was held in Brussels on 24 April 2003. It was organised by the European Commission in co-operation between DG Research and DG Agriculture and was opened by Research Commissioner Busquin and Agricultural Commissioner Fischler. The report including all the speakers' presentations is available at: http:// europa.eu.int/comm/research/biosociety/index_en.htm. This editorial is based on a scientific and technical summary of the Round Table written by Joachim Schiemann, Willy de Greef, Søren Mikkelsen, Antoine Messéan, and Jeremy Sweet.
The objective of the Round Table was to present research results, technical possibilities and farming practices relevant to ensure co-existence between GM and non-GM crops in Europe. Focus was on primary production on the farm up to the first point of sale, i.e. "from seed to silo". The Round Table did not consider pharmaceutical and industrial crops. The objective was furthermore to discuss the scientific and technical evidence with the stakeholders involved.

The Round Table specifically addressed two crops, maize and oilseed rape. These are among the candidates for large-scale cultivation in Europe and are among the most problematic crops in terms of ensuring coexistence.

It was recognized in the introductory presentations and on several occasions during the day that the question of ensuring co-existence between different production lines is not new to agriculture. Valuable experience exists from other production systems, which has been used to inform GM stewardship schemes even if they are not directly applicable (different thresholds, economic conditions and organization schemes).

\section{LESSONS LEARNED}

Segregation of crops to a defined standard of purity is not new. The development of seed production of pure varieties of most commodity crops depends on the ability to provide effective isolation in order to grow pure seed and minimize the possibility of the influx of genes from mainstream crop production of the same species.

Co-existence of different types of the same species of crops in farming systems for different uses in the processing industry is a common practise in modern farming. For example, commodity yellow dent field maize (the type that makes up most of the maize grown for animal feed) co-exists in European agriculture with 


\section{J. Schiemann}

several types of "speciality maize" such as sweet maize or sweet corn (the type sold for human consumption, both as fresh produce and in cans) and waxy maize, a type grown for the starch industry. Similarly, oilseed rape for human and animal consumption is grown in the same regions as industrial high erucic acid rape, which is not allowed in the food chain. Operating procedures to allow these crops to be grown in the same region and deliver them to their respective processing stream with a high level of confidence are routine in the agricultural industry.

The measures needed to achieve a desired standard of purity in delivering two or more streams of segregated types of the same crop depend on the biology of each crop, and on the standard agricultural practices in place.

- The most important biological parameters are flowering biology (mainly the ability of pollen to move from one type of crop to another), the ability of the crop to make fertile crosses with related wild relatives that may grow in or around the production field, and the survival ability of its seed and other storage structures if they are left in the field.

- These biological parameters are influenced by the environment (for example, the windiness of the environment in which they are grown will affect the probable area of spread of pollen from a wind-pollinated crop like maize).

- Farming systems and traditions vary widely throughout the EU. Field size and crop rotation affect the probability that two distinct types of the same crop are grown side by side or in close succession. They also affect the measures needed (e.g. collaboration between neighboring farmers) to achieve crop segregation.

- Last, the standards of purity needed for serving different markets with different types of the same crop strongly affect the possibility of growing them in the close proximity.

The higher the standards of crop purity, the lower are the tolerances for admixture, and the greater the spatial and temporal isolation measures needed to achieve this high purity. For example, high quality basic seed (the material used to plant certified seed production fields) requires higher purity standards (in other words, extremely low allowance for influx of foreign pollen or seed), so it is usually grown with very large spatial and temporal isolation from other sources of the same crop. Certified seed production of the same crop usually allows slightly lower levels of purity, and therefore isolation requirements are reduced accordingly. The costs of achieving varietal purity increase proportionately with the level of purity required because of the increased costs of isolation, monitoring, testing for purity, using dedicated equipment, or cleaning equipment, etc.

Zero tolerance for gene exchange is not practical on a routine basis. This standard is most closely approached in the early stages of multiplication of seed varieties, but this happens on very small acreages, and under levels of management that make the production cost many times more than what can realistically be charged for a food crop. As long as a crop is capable of producing pollen and/or producing survival structures such as seed, there is always a measurable probability that this pollen or seed will move or reproduce. For example, large scale surveys of conventional herbicide-tolerant oilseed rape in Australia have shown that while the probability of outflow of pollen drops rapidly beyond the field border, it does not come down to zero for a very long distance.

This also has implications for research and experimental releases of GM food crops. Zero thresholds for these transgenes in commercial non-GM crops is in some cases not feasible and, if imposed, would severely restrict and inhibit experimental development of new GM crops. A threshold needs to be agreed. On the other hand, environmental and biosafety safeguards are required to limit gene flow as much as is practically feasible.

There is experience in the EU with co-existence between GM and non-GM crops in a viable way: In Spain, 20-25000 ha of GM maize is cultivated by farmers annually in areas where conventional and organic maize are also produced. The systems developed to maintain the different product streams of GM feed maize and non-GM food maize have been found to work reliably.

The SCIMAC stewardship system operated in the UK on the Farm Scale Evaluation program of GM crops was based on procedures for certified seed production and was largely supported by the farmers who used it.

Well-developed crop stewardship programs for all the co-existing systems are important. However, it has become routine for most EU farmers to work under specified crop quality assurance (QA) programs. A significant part of EU agricultural production today is produced under contract and under QA systems. There are therefore models from which to work, and there is a body of experience in the farming community with stewardship programs: for example, the quality management programs imposed by the food distribution companies. Nevertheless, if analysis of past experiences is valuable, their specificities should be taken into account in order to figure out what is meaningful for GM/non-GM co-existence. 


\section{IMPLICATIONS FOR MAIZE AND OILSEED RAPE}

\section{Maize}

Adventitious presence of GM seeds in non-GM maize harvest may have several causes:

- Cross pollination between non-GM crops and a neighboring GM maize field through pollen transfer;

- GM impurities in seed lots (cross-pollination during field production or admixture during post-harvest processing).

Practical and technical knowledge is now available on pollen dispersal. Models have been developed and validated for short distances and homogeneous landscapes. Prediction at long distances and taking into account fragmented landscapes should be refined.

Experience of co-existence for conventional products has been reported. It has been emphasized that co-existence is possible, but that its technical feasibility and the economic costs depend greatly on the threshold. Conditions of such productions (organisation, stewardship, prices, etc.) are all specific ones. Current co-existence schemes are based on a balance between quality or purity requirements and costs for achieving those requirements: thus the threshold to be achieved results from a "compromise".

Spain has been growing GM maize for several years and the GM production is used for feeding animals. Segregation between organic, non-GM and GM maize has been implemented through a dialog between stakeholders. Under such specific conditions (one GM variety grown, 10 to $13 \%$ of the maize acreage), coexistence between GM and non-GM products has been made possible. However, a zero-threshold was not achievable in all situations.

Several studies on co-existence between GM and non-GM crops, based on existing data, expertise and models, have been carried out. Co-existence for maize grain production is feasible under some conditions but should be considered on a case-by-case basis: crops, farming systems, location site, products, etc. Depending on these situations and on the threshold, specific guidelines have to be implemented, either on an individual basis (crop management guidelines) or on a collective basis (sharing information, contracts, buffer zones, etc.).

The following questions are still open:

- Pollen flow at large distances (several hundreds meters) and over fragmented landscapes is low but rather erratic. Insufficient data have been collected at this level.
- The level of adoption of GM maize would have a major effect in terms of GM pollen pressure. Experimental data collected from small field trials and models have been used to forecast the behavior under large scale cultivation. However, field data obtained at a larger scale (either from trials or from commercial fields) would be useful to provide more evidence of model prediction and evaluation.

- The question of cross-border GM adventitious presence has been raised and linked to the feasibility of preserving GMO-free zones in Europe. How should we define and manage buffer zones between GMO-free zones and regions with co-existence?

\section{Oilseed Rape}

Oilseed rape is an out-crossing species with very effective seed dispersal mechanisms in agricultural practise. Thresholds for seed and crop purity need to reflect this since it is unrealistic and impractical to try to achieve zero thresholds or even thresholds approaching zero. It is estimated that 3000 seeds need to be tested to determine a $0.1 \%$ threshold at around $95 \%$ certainty. This is considered to be the limit of realistic testing with the present state of technology, and bearing in mind costs of sampling and testing. In oilseed rape, a threshold of $0.3 \%$ for certified seed is recommended in order for farmers to achieve below $0.9-1.0 \%$ threshold for crops. Some sectors of industry argued for higher thresholds stating that there are no scientific, health or safety reasons for the current proposed levels, and the proposed levels of threshold for GM will impose unreasonable costs on seeds and foods and inhibit new innovation. The organic movement has argued for lower thresholds saying that current proposed thresholds will deny access to "GMfree" foods. Some countries (e.g. Austria) are testing to "zero" presence of GMOs in seed and certain crop products (in fact this is probably a threshold of $0.1 \%$ ). However it was certainly recognized by all that the lower the threshold the more extensive and expensive are the measures needed to achieve this purity.

Farms, field sizes, farming systems, crop rotations and cropping patterns vary tremendously across Europe. It is imperative that this variability is taken into account when devising systems for managing and coordinating co-existence measures. The measures that are applied must be appropriate, specific to the cropping system on the farm and take account of local and regional farming systems.

Thus subsidiarity is needed for decisions on appropriate measures for co-existence taking account of 


\section{J. Schiemann}

the local factors. The agricultural communities in each Member State or region of Member State should establish their measures, following general guidance from EU and agreement on the thresholds required. However there may be difficulties at the borders between countries where farm borders do not coincide with national borders and national measures for co-existence.

It is not considered appropriate to have centrally directed management procedures, even though there is a feeling that some sectors of farming (e.g. organic) may be disproportionately treated in different member states.

\section{RESEARCH NEEDS}

Technical, organisational and economic retrospective analysis of past and current experience of co-existence should be performed in order to understand their specific attributes and their relevance for GM/non-GM coexistence.

Landscape scale and long distance gene flow experiments are necessary in order to provide data for developing models and verification of predictions from these models. The early years of commercial releases (e.g. Spain) should be used for this purpose as well as studies of current cropping practices using varietalspecific markers.

Predictive models that operate at the landscape and regional levels need to be developed in order to help decision-makers (farmers, stakeholders, regulation bodies) in the pre- and post-marketing management of the introduction of GM crops.

Implementation of monitoring schemes for coexistence (as distinct from monitoring for potential negative impacts) requires a general framework, methods and tools for:

- Establishing baselines (landscape patterns, farming systems);

- Designing protocols for monitoring gene flow (e.g. sampling procedures);

- Implementing tools for re-assessing and updating coexistence measures.

Information is needed to provide accurate guidance to farmers and agronomists on the management of GM and non-GM crops. Specifically it was recognized that further information is needed on:

- The impacts of scaling up GM oilseed rape crop production on levels of pollen dispersal and out-crossing especially at longer distances.

- The accumulation of GM seed in seed banks when GM oilseed rape is widely grown for several years and subsequent levels of admixture in harvested crops.
- Implementation of monitoring schemes for coexistence: step-by-step introduction of GM crops would allow research to keep pace with introduction. Monitoring will be an important part of the introductory process and should include monitoring of gene flow to adjacent GM crops. Monitoring these introductions would thus supply information relevant to the evolution of appropriate co-existence measures.

- Methods are required for estimating the costs of coexistence at the farm and regional level by taking into account bio-geographical diversity and the changes in agricultural practices that are needed. Economic impacts should be assessed for organic, non-GM and GM farming systems. Methods for assessing and assigning liability for co-existence at the farm level are required that take account of accepted agricultural practices and current law.

In addition, it was considered important that further research was conducted on methods for restricting gene flow by eliminating the fertility of pollen or seeds (e.g. through apomixis, cytoplasmic male sterility, etc.).

\section{RECOMMENDATIONS}

\section{Forecasting}

Forecasting the impacts of co-existence is a major challenge, and it should be addressed before marketing as far as it is possible. For such a perspective, models are useful but field data remain necessary through large scale experiments or through monitoring commercial releases.

\section{Thresholds}

Thresholds as key parameters for co-existence should be established for all different kinds of agricultural production.

\section{Co-existence Measures}

These should be science-based and utilize existing crop purity systems and assurance programs. They should be based on the characteristics of the crop, the farming system and regional requirements. They should be developed so that they are appropriate for the thresholds set for GM admixture. Considerable experience has already been achieved in segregating industrial and food rape crops and in certified seed production. The SCIMAC system for controlling GM crop production in the UK was derived from seed production systems, and appears to be working well on the Farm Scale Evaluation 
Program. However co-existence and segregation systems need to be flexible and evolve with changing farming requirements. They need to take into account future GM crops coming through research programs.

\section{Monitoring}

The introduction of GM crops in existing farming systems will require monitoring to verify the models and predictions about cost, isolation standards, and generally to learn how the farming community copes with the requirements for keeping the product streams separated. Therefore, a system of managed introduction, with increasing acreage year by year, accompanied by a monitoring effort appropriate to generate the data needed for management decisions is recommended.

\section{Dialog}

It is recommended that strategy development takes place in a dialog between the scientific and technical community and all relevant stakeholders. Based on experiences from the Danish approach, such dialog should be organized with due consideration and respect of the integrity and requirements of each of these participants.

\section{Stewardship}

Stewardship programs should take into account the interests of both GM and non-GM farmers. Existing product stewardship programs for non-GM crops in farming should be a starting point for developing stewardship schemes for GM crops. They should be studied in more detail, because they are tried and tested on the farm, and adaptations of them to suit the needs of co-existence between GM, non-GM and organic crops are more likely to work effectively. Stewardship will be in the hands of the farmers and other local operators, and thus stewardship schemes must be compatible with other farming operations, practical and inexpensive to operate and monitor/audit.

\section{Research}

The scientific community should be encouraged to fill the knowledge gaps that have been identified. A close partnership between national research programs on aspects of co-existence and EU-funded programmes should be established under the leadership of the EU. Framework Program 6 should provide the basis for EU-wide pilot projects to validate models and guidelines, including long-term studies. Building up mechanistic, probabilistic, and predictive models of gene flow should be supported.

A step by step managed introduction of GM plants, linked with biosafety research, monitoring and validation should provide the necessary basis for further studies.

\section{RECOMMENDATION OF THE COMMISSION OF THE EUROPEAN COMMUNITIES ON CO-EXISTENCE GUIDELINES}

On 23 July 2003 the EC Commission published a Commission Recommendation on guidelines for the development of national strategies and best practices to ensure the co-existence of genetically modified crops with conventional and organic farming. It states that "no form of agriculture, be it conventional, organic, or agriculture using GMOs, should be excluded in the European Union".

In November 2003, the first European Conference on Co-existence was held Denmark ${ }^{1}$.

\section{ACKNOWLEDGEMENTS}

I would like to thank the co-authors of the scientific and technical summary of the Round Table, Willy de Greef, Søren Mikkelsen, Antoine Messéan, and Jeremy Sweet for providing the basis for this editorial.

\footnotetext{
1 1st European Conference on the Co-existence of Genetically Modified Crops with Conventional and Organic Crops, GMCC-03, took place on 13-14 November 2003 in Helsingør, Denmark, www.agrsci.dk/GMCC-03
} 